\title{
GEOGRAFIA DE LA DEMOCRACIA: ESPACIO POLÍTICO ABIERTO EN CONFLICTO EN LA ELECCÍON PRESIDENCIAL DE 2018 EN MEXICO
}

\author{
Daniel A. de Azevedo* \\ Universidade de Brasília \\ Denisse E. Hérnandez Linares** \\ Universidad Nacional Autónoma de México
}

\begin{abstract}
Resumen: El presente artículo tiene como objetivo analizar la importancia del eje Paseo de la Reforma-Zócalo como espacio político abierto en México, a partir de la premisa de que la democracia se ejerce mejor con una mayor difusión y calidad de los espacios políticos. Se busca considerar ese eje espacial como protagonista y no sólo escenario de eventos políticos. El artículo presenta así una geografía de la democracia y coloca el concepto de espacio político en el centro del debate, evidenciado en el proceso electoral presidencial de 2018. La metodología de investigación combina dos estrategias: análisis de los principales periódicos sobre los usos de espacios abiertos y entrevistas con organizadores y partidarios. De este modo, se expone el carácter espacial de la democracia en acción y subraya la importancia de los espacios políticos para produndizar la legitimidad de la democracia cotidiana.
\end{abstract}

Palabras clave: espacio político, democracia, Zócalo, Paseo de la Reforma, elecciones mexicanas.

\section{GEOGRAPHY OF DEMOCRACY: OPEN POLITICAL SPACE IN CONFLICT IN THE 2018 PRESIDENTIAL ELECTION IN MEXICO}

Abstract: This article aims to analyze the importance of the Paseo de la Reforma-Zócalo axis as an open political space in Mexico, based on the premise that democracy is best exercised with greater dissemination and quality of political spaces. It seeks to consider that space axis as the protagonist and not just the scene of political events. The article thus presents a geography of democracy and places the concept of political space at the center of the debate, evidenced in the 2018 presidential electoral process. The research methodology combines two strategies: analysis of the main newspapers on the uses of open spaces and interviews with organizers and supporters. In this way, the spatial character of democracy in action is exposed and underlines the importance of political spaces to deepen the legitimacy of everyday democracy.

Keywords: political space, democracy, Zocalo, Paseo de la Reforma, Mexican elections.

\section{GEOGRAFIA DA DEMOCRACIA: ESPAÇO POLÍTICO ABERTO EM CONFLITO NAS ELEIÇÕES PRESIDENCIAIS DE 2018 NO MÉXICO}

Resumo: Este artigo tem como objetivo analisar a importância do eixo Paseo da Reforma-Zócalo como um espaço político aberto no México, com base na premissa de que a democracia é melhor exercida com maior difusão e qualidade dos espaços políticos. Procura-se considerar esse eixo espacial como protagonista e não apenas cenário de eventos políticos. 0 artigo apresenta uma geografia da democracia e coloca o conceito de espaço político no centro do debate, evidenciado no processo eleitoral presidencial de 2018. A metodologia de pesquisa combina duas estratégias: análise dos principais jornais sobre o uso de espaços abertos e entrevistas com organizadores e apoiadores. Desse modo, o caráter espacial da democracia em ação é exposto e sublinha-se a importância dos espaços políticos para o aprofundamento e maior legitimidade da democracia cotidiana.

Palavras-chave: espaço político, democracia, Zócalo, Paseo de la Reforma, eleições no México. 


\section{Introducción: objetivos y justificación}

El 24 de abril de 2018, el entonces candidato a Jefe de Gobierno de la Ciudad de México por el Partido Revolucionario Institucional (PRI), declaró en su red social (Facebook) que, si fuera elegido, desde el primer día, regularía las marchas porque, según él, "¡no más afectaciones a las mayorías! ¡Es injusto que pocas personas afecten a muchos en su productividad y el tiempo que pasan con su familia!". Este discurso se relaciona con la publicación de hace más de un año antes del periódico más leído del país: el día 02 de marzo de 2017, el reportaje de El Universal titulado "CDMX, ciudad de marchas y ganancias millonarias" reveló que "cada inicio de año, cientos de movilizaciones paran la capital. Se calcula que se pierden 17 millones de pesos en ventas por cada dos horas que dura una manifestación" (Guazo, 2017).

Las declaraciones de políticos y medios sobre las manifestaciones en la capital mexicana revelan el intenso conflicto que existe en el país por el uso de espacios políticos abiertos. Este artículo revela la espacialidad de los movimientos políticos a partir del concepto de espacio político abierto y percibe la elección mexicana de 2018 como un momento crucial en que fue posible notar la importancia estratégica de estos mismos para la geografía de la y para la democracia. La premisa de la que se parte es que la democracia es un fenómeno también espacial, es decir, hay una espacialidad inherente en la democracia teórica y en la democracia que se practica cotidianamente.

El trabajo está dividido en tres partes: en la primera, se define el marco teórico utilizado para el abordaje analítico, a partir de diferentes autores dentro de las ciencias humanas, principalmente de la ciencia política y de la geografía política. En la segunda, se presenta la metodología y la base de datos utilizada en la conformación del trabajo, que incluye producción de datos de fuentes primarias, como reportajes de importantes periódicos mexicanos y trabajo de campo usando surveys y entrevistas. En la tercera, se hace referencia a los datos sobre protestas políticas en los últimos tres años en el país, para buscar patrones espaciales que ayuden a entender la complejidad de la democracia mexicana. Asimismo, en esta última se analizan los trabajos de campo efectuados durante los dos meses anteriores a la elección mexicana y en el cierre de la campaña presidencial.

El concepto de espacio político funciona como una herramienta geográfica de puente entre los estudios sobre democracia en la ciencia política y la espacialidad de la geografía. Aquí se afirma que la democracia es más que elecciones, es decir, ese momento importante de la democracia representativa no es el unico proceso para la política. El uso de espacios políticos abiertos (a partir de protestas, manifestaciones, mítines, etc.) también es fundamental para un buen funcionamiento de los derechos de la democracia de consentir y disentir. Democracia es también un concepto espacial' ${ }^{1}$.

\section{Democracia, los espacios políticos y sus características}

Es importante definir lo que se entiende en ese texto como sistema político democrático. Es posible partir de una definición básica y expandirla: en resumen, el sistema político democrático posee tres valores fundamentales: (a) gobierno de la mayoría, sin exclusión de la minoría, respetando la pluralidad humana ${ }^{2}$ (Kelsen, 2000, Bobbio, 2007, Tilly, 2007, Dahl, 2009, Arendt, 2009a, Held, 2012) (b) necesidad de instituciones de poder (Hall, 1992; Smith, 1992; Mann, 1992) y (c) participación de todos los ciudadanos para la formulación de las normas sociales, directa, indirectamente, o una mezcla de los dos modos ${ }^{3}$. Sin embargo, corresponde a la geografía política una expansión necesaria del concepto de democracia anteriormente presentado.

Los geógrafos políticos expusieron la espacialidad de la democracia, en la discusión sobre la geografía del voto (Magdaleno, 2010; Juwer, 2012; Resnick, 2017), en la relación entre institución y territorio (Cox, Reynolds \& Rokkan, 1974; Nunes \& Sanfelici, 2018), en la espacialidad de los movimientos sociales (Painter \& Jaffrey, 2009; Cisternas \& Contreras, 2018), y, más recientemente, cuando el concepto de espacio político fue discutido y definido (Castro, 2012; 2018; Azevedo \& Sotelo, 2018; Azevedo, 2018a; Machado Filho, 2018; Azevedo, 2019), trayendo una nueva perspectiva sobre la espacialidad de la democracia. Es preciso destacar que la democracia en acción necesita de espacios políticos para su realización, en otras palabras, como afirma el científico político de gran sensibilidad espacial Norberto Bobbio (2000, p.

1 Nota de los autores: agradecemos las contribuciones de los revisores de la revista GEOgraphia. Dichas observaciones serán útiles para mejorar este texto, ser más claro y una buena contribución a la Geografía Política.

2 Cabe resaltar que esa característica se desarrolló con la unión de los valores democráticos y liberales, en un intento de eliminación de las críticas platónicas en La República y de Alexis de Tocqueville en La Democracia en América. Ambos autores desconfiaban del sistema político democrático porque creían que había un germen autoritario - de la mayoría - en esa forma de gobierno. Las discusiones posteriores de Benjamin Constant, John Stuart Mill, Robert Dahl, Norberto Bobbio y Hannah Arendt expandieron la definición de democracia más allá del poder de la mayoría, siendo también la defensa de los derechos de las minorías.

3 Los grandes debates ya han sido hechos sobre la superioridad o la inferioridad del sistema representativo. Para la literatura clásica sobre el tema, ver Los Federalistas (James Madison, Alexander Hamilton y John Jay), Consideraciones sobre el Sistema Representativo (J.S. Mill) y El espíritu de las Leyes (Montesquieu) 
40), cuando se desea "saber si ha habido un desarrollo de la democracia en un país, no se trata solamente de percibir si ha aumentado o no el número de los que tienen el derecho de participar en las decisiones que le conciernen, sino los espacios en los que pueden ejercer este derecho".

El espacio político está definido como el espacio materialmente construido que sirve como intermediación y condiciona las relaciones entre Estado y sociedad. En él, los actos políticos toman cuerpo, ganan visibilidad y pueden influir en la agenda política del poder instituyente. Uno de los propósitos de este artículo es, pues, contribuir al debate sobre el espacio político como un concepto posible de ser usado para la interpretación de prácticas políticas, a diferencia de su historia en la disciplina que nunca se configuró como un concepto consolidado (Castro, 2018).

El espacio político es, entonces, material, inmaterial e intencional. Al afirmar que este concepto es material no se considera el mundo virtual como espacio político. El mundo virtual es una zona de confort para sus integrantes, en la que se puede hablar y escuchar sólo lo que se quiere. Se excluye lo que no se quiere y no gusta. Además, la necesidad de ser alfabetizadas y que posean equipamientos tecnológicos para participar, excluye a una parte de la población, especialmente en países con gran pobreza. El espacio político es la zona de riesgo, donde los diferentes se encuentran, hablan y tienen que escucharse - por eso, es allí donde la democracia se construye y se fortalece, donde los humanos comparten actos y palabras. El mundo virtual fue fundamental para acercar a las personas y, por eso, la capacidad de acción se amplió, ya que cuando los hombres, según Wagner (2000, p.53) "viven tan cerca unos a otros, las potencialidades de la acción están siempre presentes".

Es importante señalar que el espacio político es el lugar de encuentro de los diferentes, no es un espacio armónico, pero tampoco es donde se usa la fuerza. Aquí, otra vez, usamos las consideraciones de Arendt (2009), que afirma que donde la fuerza se establece, la política ya desapareció. Los conflictos sociales - de clase, de raza, género, orientación sexual, etc. - ganan visibilidad en los espacios políticos y claro, estos funcionan como un amplificador de las competencias existentes entre grupos, incluso de los intentos de dejar fuera de esos espacios grupos divergentes. Sin embargo, luchas sociales son posibles y esperadas, pero la búsqueda de borrar la existencia de grupos diferentes en la sociedad es un intento contra la propia idea de democracia.

El espacio político promueve el encuentro entre los diferentes y la interacción cara a cara, haciendo posible la construcción de una verdadera pedagogía de la democracia, es donde los hombres realizan su plena humanidad, "su plena realidad como hombres, no sólo porque son (como en la privacidad de la vida familiar), sino también porque aparecen" (Arendt, 2009b, p.64, grifo en el original). Estas características hacen que el espacio político sea un agente de intersección del Estado democrático, haciéndolo, en cierto modo, más o menos intensamente un espacio institucional. Como la intencionalidad de su existencia es la acción, es el espacio donde la sociedad tiene contacto directo con las instituciones del poder para influenciarlo por medio de la simple presión de la presencia en conjunto o incluso por la posibilidad de actuar activamente. Como toda la obra de Hannah Arendt destaca, la acción es siempre intencional, fugaz e imprevisible, es decir, los humanos actúan buscando un fin, pero a partir del momento en que la inicia, se pierde el control sobre sus resultados.

La relación existente entre el espacio político y el Estado se construye en dos sentidos: primero, en la relación pasiva del primero en relación al segundo, pues está regulado y limitado por las reglas de convivencia social dentro de una noción de libertad democrática. Al final, la proximidad entre los hombres y la consiguiente convivencia de la pluralidad humana sólo es posible por la existencia de un "acuerdo frágil y temporal de muchas voluntades e intenciones" (Arendt, 2009a, p.71); $y$, segundo, en su papel activo como zona de contacto entre la sociedad y las fuerzas del poder instituyente, construyendo posibilidades de influir directamente en la agenda política. Por estas razones, los espacios políticos no existen a priori, pues, es la intencionalidad de la acción para tocar la agenda política que difiere un espacio público de un espacio político (Lee, 2009; Azevedo, 2018a, Castro, 2018, Machado Filho, 2018). Es decir, "el espacio público se convierte en espacio político cuando es creado y defendido por la acción política de las personas" (Lee, 2009, p.35).

Por esa razón, las movilizaciones en una sociedad democrática no están en contra del orden público, sino que pertenecen a ella, o sea, "la acción muda no existe, o si existe, es irrelevante; sin la palabra la acción pierde al actor" (Wagner, 2000, p.73). Impedir manifestaciones políticas en la sociedad dirigida por la democracia representativa es, pues, un ataque a la pluralidad humana y la política, ya que la acción es la propia libertad y ésta es el sentido de la política. Es en el espacio político, por lo tanto, la acción y la palabra son amplificadas y pueden de hecho influir en la agenda política.

Es importante destacar que al defender la acción como una característica humana proveniente de 
nuestra pluralidad, se valora la política y su inherente imprevisibilidad. De este modo, la definición de espacio político aquí se aleja de las defensas hegeliana y marxiana de la historia como un proceso coherente, en el cual las repercusiones se vuelven previsibles. Es en el espacio político donde es posible percibir que los hechos y eventos son siempre inesperados y sus sentidos le son propios, no estando subordinados a leyes y designios inmutables. Al someter los acontecimientos al patrón de lucha de clases, la teoría marxiana borró la pluralidad humana y su capacidad imprevisible de acción (Arendt, 2009c). Posicionar, pues, el espacio político en el centro del debate es devolver a los hombres su capacidad de acción y de cambio en la propia vida y la sociedad.

Por último, cabe resaltar que se denominan espacios políticos aquellos que funcionan dentro de regímenes democráticos, pues, la política delimita las reglas de la interacción social, con normas de control y de coerción legitimados por los actores sociales (Arendt, 2009a). Al seguir esa línea teórico-conceptual, no estamos aquí borrando la importancia de los espacios de subversión para la fundación de una sociedad democrática. En los momentos de dictaduras militares y civiles, los espacios políticos son suspendidos por la fuerza autoritaria de un régimen y, en su lugar, pueden entrar en escena los espacios de subversión, que son espacios para la política y no espacios políticos tout court, como definimos aquí.

Esta estrategia analítica se basa en la construcción teórico-conceptual realizada: al definir el espacio político como intersección entre Estado democrático y sociedad, se excluyen, por consiguiente, los espacios de subversión, que por su propia naturaleza, son construidos y utilizados en oposición a la forma de Estado y al sistema político existentes en el momento. Los espacios políticos, a pesar de ambientes contestatários, no objetivan la destrucción de la forma democrática del Estado: ellos sirven, por el contrario, para su preservación y fortalecimiento (Castro, 2012; Azevedo, 2018b). Esta defensa se remonta a autores clásicos como Montesquieu, que desde entonces afirmaba que la tiranía no se configuraba como un auténtico cuerpo político, pues el miedo poseía un principio antipolítico.

En concordancia con esta caracterización general aquí expuesta, Castro (2018) identifica tres tipos básicos de espacios políticos: a partir de los criterios de escala, métrica y sustancia (Lévy, 1999) como fundamentos, respectivamente, de su visibilidad (reconocimiento), abarcamiento (alcance) y efectividad (efectos deseados), la autora distingue los espacios políticos exclusivos, los espacios políticos limitados y los espacios políticos abiertos. A pesar de ser sólo ejemplos ya conocidos y en modo alguno ser excluyentes a otros que puedan existir, es posible ejemplificar posibles espacios políticos a partir de esa tipificación realizada por la autora.

Los espacios políticos exclusivos poseen amplia visibilidad y reconocimiento formales y pueden ser los Parlamentos, las Asambleas o Cámaras Legislativas. Los espacios políticos limitados corresponderían a los espacios que poseen una clara demarcación temática y decisiva, como ejemplos tendríamos las Asociaciones Vecinales, Consejos Ciudadanos y audiencias públicas. Es importante recordar que esos espacios son en principio espacios políticos, es decir, una Asamblea Legislativa sólo sería considerada, de hecho, espacio político si corresponde a los valores democráticos explicitados anteriormente. Hay, por ejemplo, gobiernos despóticos que mantienen sus asambleas, pero no poseen ninguna legitimidad democrática, pues sus miembros no han sido seleccionados a partir de un sufragio universal, respetando los derechos de las minorías o porque hay el impedimento formal o informal a la participación de todos los ciudadanos.

Por último, es el tercer tipo de espacio político que nos interesa en este artículo y se le pondrá mayor atención. Los espacios políticos abiertos se refieren a las plazas, calles y avenidas que se tornan arenas de demandas, conflictos y acción, lo que les impregna de carácter político (Machado Filho, 2018). Así, como Castro revela:

Su escala y métrica son variables e inestables, pero
sus efectos como condición de su sustancia pueden
afectar profundamente a algunas decisiones políticas
a largo plazo, estableciendo un nexo entre la "plaza"
y el "palacio", o más objetivamente, entre la sociedad
y sus gobernantes. Estos son espacios de acción
abiertos a toda la sociedad, cualidad intrínseca a los
espacios escogidos para manifestaciones, protestas,
marchas, ocupaciones y todo lo que la imaginación
de los activistas sociales decide crear para alcanzar
sus objetivos políticos. No está de más recordar que
cuanto más libres, numerosos y reconocidos por la
sociedad esos espacios, mayor será el vigor de su
participación política en la organización y defensa de
sus intereses. (Castro, 2018, p.123).

El uso de los espacios políticos abiertos hace posible que demandas individuales se vuelven demandas sociales y políticas, ya que los sujetos se movilizan, se encuentran e incluso a partir de sus diferencias, trazan objetivos en común. Es en el encuentro con lo diferente en el espacio político abierto que la acción es posible, 
pues la pluralidad humana se vocaliza y aparece. Al final, "vivir y actuar juntos aparecen como la única posibilidad humana en la cual la fuerza, dada por la naturaleza, puede transformarse en poder" (Arendt, 2009b, p.116).

Hay lugares que poseen una vocación espacial política, funcionando como medio y como objeto de la acción. Como dice Mitchell (2003, p.12), "el derecho a la ciudad es un grito que se oye y una demanda que tiene fuerza sólo en la medida en que existe un espacio dentro del cual ese grito y esa demanda son visibles". Hay, por lo tanto, una geografía de la democracia importante de ser evaluada e interpretada.

\section{Metodologia y base de datos}

Dos métodos fueran usados en este artículo para comprender la espacialidad de los movimientos políticos y la interpretación dada por ciudadanos a los espacios políticos usados: (a) primero, una tabulación y mapeo a partir de informaciones levantadas en dos grandes periódicos nacionales; (b) segundo, encuestas y entrevistas no estructuradas con participantes de la clausura de la campaña presidencial de Andrés Manuel Lopéz Obrador (96 surveys) y miembros de su campaña electoral (diez entrevistados). Estas dos fuentes de datos primarios se unieron a la base de datos proporcionada por la Secretaría de Seguridad Pública de la Ciudad de México, por medio de la Ley de Transparencia Pública. En una solicitud oficial, la institución respondió con rapidez al pedido del número total de manifestaciones, pero dijo no tener la ubicación de cada una ${ }^{4}$.

La falta de información pública sobre la ubicación de los usos de espacios políticos abiertos no se configuró como un problema para la investigación, pues la idea era buscar los movimientos políticos con mayor visibilidad en los medios. Por esa razón, se realizó el levantamiento de los últimos tres años y medio de publicación en los periódicos La Jornada y El Universal. La selección respetó la lista producida que apunta a estos dos periódicos como algunos de los más leídos en el país (Merca, 2017), además de la idea ampliamente divulgada que ellos representan visiones ideológicas distintas sobre los problemas sociopolíticos mexicanos.

Se tabularon 1050 manifestaciones noticiadas en La Jornada y 205 de El Universal en tres distintas columnas: fecha y sección del periódico, lugar de ocurrencia y razón de la manifestación. Posteriormente, en la tercera columna, las manifestaciones fueron categorizadas en

4 Según el correo electrónico recibido el 13 de agosto de 2018, de oficio número SSP / DET / UT / 4712/2018. "demanda de escala local", "demanda de escala nacional" y "demanda de escala internacional".

Cabe enfatizar por un lado que la elección de la indagatoria en los periódicos mencionados no significa en modo alguno que se considere que la protesta sólo tiene legitimidad si son cubiertos por esos medios. Por otro lado no se puede negar que el discurso construido alrededor de las manifestaciones es en gran parte responsabilidad de estos órganos informativos. Así, el análisis de cuáles y cómo esas protestas son publicadas por estos medios de comunicación es una importante forma de comprender la construcción de los discursos derivados de ellos.

La encuesta y las entrevistas pretendían recuperar el sentido espacial del Zócalo y del estadio Azteca para los participantes, para revelar la interpretación y los valores que los ciudadanos atribuyen a ambos espacios (Secor, 2010; Sepúlveda, 2018). Las técnicas utilizadas tanto en el survey como en las entrevistas abiertas siguieron lo propuesto por Anna Secor en Research Methods in Geography: a critical Introduction (Secor, 2010). La entrada con los miembros de la campaña fue posible por una técnica conocida como snowball technique, a partir de un amigo participante en el partido político Movimiento de Regeración Nacional (Morena).

Mientras que las entrevistas se realizaron durante las dos semanas anteriores al cierre, la encuesta se efectuó en la salida del evento en la puerta del estadio Azteca el 27 de junio de 2018 a partir de un muestreo no probabilístico, y un cuestionario con seis preguntas: cinco de carácter clasificatorio (edad, ocupación, renta media, lugar de origen y los medios de transporte para llegar al evento) y una con enfoque más exploratorio consistente con los objetivos de este estudio: (1) ¿Dónde prefiere el cierre de campaña: Zócalo o estadio Azteca? ¿Por qué?

Se realizaron 96 encuestas en el día de cierre de la campaña del candidato, respetando el cálculo muestral en un universo de 90 mil participantes, con $10 \%$ de margen de error y $95 \%$ de confiabilidad. Las respuestas de las entrevistas no estructuradas y las encuestas fueron sistematizadas a partir del software Maxqda, organizado a partir de tres indexadores relacionados a la base teórica discutida: (a) materialidad; (b) inmaterialidad; (c) intencionalidad. Así, fue posible cruzar la información suministrada y discutir las principales interpretaciones espaciales traídas por los informantes. Cabe señalar que aquí se defiende, por lo tanto, la postura de que no existe una superioridad metodológica cuantitativa con relación 
a la investigación cualitativa, es decir, investigaciones espaciales pueden utilizar de ambas técnicas como modo de complementariedad.

Uso político de los espacios en la capital mexicana: el eje Paseo de La Reforma-Zócalo y la disputa por el espacio político abierto

En investigación desarrollada entre los meses de mayo a septiembre de 2018, fue posible identificar la cantidad de manifestaciones políticas $^{5}$ en espacios

5 Aquí se denominarán genéricamente de "manifestaciones políticas" las protestas, barricadas, ocupaciones, caravanas, etc., o sea, todo tipo de usos de espacios políticos abiertos. políticos abiertos en México. Según datos de la Secretaría de Seguridad Pública de la Ciudad de México, hubo 22.107 usos de espacios políticos abiertos en el país en los últimos tres años, es decir, un promedio de veinte por día. Este impresionante número puede al mismo tiempo plantear cuestiones negativas sobre la situación socioeconomica del país. En el Cuadro 1, es posible percibir en la tabla más de diez categorías de uso del espacio político abierto mencionadas por el poder público.

Cuadro 1 - Usos de espacio político abierto en México (2015-2017)

\begin{tabular}{|c|c|c|c|c|c|c|}
\hline \multirow{2}{*}{ Movilizaciones } & \multicolumn{2}{|c|}{2015} & \multicolumn{2}{|c|}{2016} & \multicolumn{2}{|c|}{2017} \\
\hline & Mov. & Part. & Mov. & Part. & Mov. & Part. \\
\hline Mítines & 468 & 607,603 & 331 & 520,773 & 405 & 392,377 \\
\hline Marchas & 773 & 553,165 & 657 & 695,118 & 654 & 656,106 \\
\hline Caravanas & 207 & 47,259 & 162 & 69,914 & 181 & 45,987 \\
\hline Plantones & 50 & 43,577 & 35 & 13,317 & 32 & 24,572 \\
\hline Concentraciones & 4,170 & $1 ' 085,283$ & 3,961 & 907,182 & 4,316 & 1'182,961 \\
\hline Bloqueos Viales & 1,188 & 779,522 & 1,278 & $1 ' 042,516$ & 1,391 & 891,023 \\
\hline Toma de Instalaciones & 3 & 960 & 1 & 20 & - & - \\
\hline $\begin{array}{l}\text { Asambleas } \\
\text { Informativas }\end{array}$ & 231 & 37,113 & 250 & 47,144 & 241 & 53,633 \\
\hline Otros $^{*}$ & 330 & 138,937 & 336 & 259,433 & 456 & 725,277 \\
\hline TOTAL & 7,420 & 3'293,419 & 7,011 & 3'555,417 & 7,676 & 3'971,936 \\
\hline
\end{tabular}

*Otros: Bloqueos de Accesos a Inmuebles, Huelgas de Hambre, Conferencias de Prensa, Eventos Políticos, Semáforos Informativos, etc.

Fuente: Secretaría de Seguridad Pública de Ciudad de México, 2018.

Estos datos fueron intensamente utilizados por los medios para señalar a menudo cómo era excesivo el número de manifestaciones políticas en el país en los últimos años y de qué modo afectaba la economía de muchas ciudades, incluyendo principalmente la capital del país (Hernandez, 2017; Arredondo, 2018). A pesar de ser evidente la importancia de nuevas estrategias de visibilidad y publicidad de los movimientos sociales a partir de las redes virtuales (Castells, 2015; FloresMarquez, 2016), los medios tradicionales (periódicos, televisión y radio) siguen siendo fundamentales para la construcción de discursos sobre las manifestaciones en México, como apuntan las investigaciones de Pastrana (2011) y Rovira-Sancho (2013). Este último autor afirma que "todo movimiento social busca llegar a sensibilizar a una amplia opinión pública que considere sus protestas en el modo de acontecimientos, como parte de una exigencia razonable de justicia" (Rovira-Sancho, 2013, p.35).

Los medios de comunicación son un importante modo de hacer visible o invisible los movimientos políticos, pues conforman sus representaciones, imágenes y discursos, exteriormente y también dentro del propio grupo. Al saber que las actividades de protesta pueden ser transmitidas por televisión y periódicos, se configura una disposición diferente de la acción colectiva, teniendo un papel fundamental en la teatralidad de la política (Codato, 2011) ${ }^{6}$, produciendo lo que Giltin (1980) denomina como el síndrome de "todo el mundo está mirando".

La visibilidad de los movimientos políticos es característica fundamental para la atención de las

6 Se destaca que no se pone carga peyorativa en la idea de teatralidad de la política, como lo hizo Karl Marx en el 18 Brumario de Luis Bonaparte, al asociar escenificación a la falsedad. 
demandas. El espacio geográfico convertido en espacio político es seleccionado por los grupos a partir de su capacidad de visibilización: el espacio político no es elegido de modo aleatorio para la acción, sino que son elegidos a partir de sus características espaciales materiales y simbólicas. Defendemos que el lugar de los movimientos políticos tiene un papel fundamental en su visibilidad, es decir, hay espacios políticos que en la divulgación mediática no se pueden negar.

El levantamiento en los últimos tres años y medio de las publicaciones de los periódicos La Jornada y El Universal acerca de manifestaciones políticas en todo México, reveló los espacios políticos más o menos importantes en el país, sus concentraciones o dispersiones espaciales. Interesante también fue la discrepancia de la preocupación de los diferentes periódicos para divulgar manifestaciones: entre el período de enero de 2015 al 01 de julio de 2018 el periódico El Universal reportó 205 manifestaciones, mientras que La Jornada destacó 1050. Además, el periódico El Universal priorizó las manifestaciones políticas que tenían demandas de escala nacional (58\% de todos las noticias), mientras que La Jornada puso más atención a las de escala local $(60,63 \%)$, discrepancia que podría ser en un trabajo futuro un foco interesante de atención.

$\mathrm{Si}$, por un lado, esa diferencia puede servir para corroborar la selección de esos dos periódicos, por otro lado, los datos presentados por ambos todavía están por debajo del total informado por la Secretaría de Seguridad Pública de la Ciudad de México. Esto demuestra que hay una selección editorial sobrelas manifestaciones políticas que deberían estar o no cubiertas. Al tabular todos los datos obtenidos fue posible percibir un patrón espacial de concentración de los movimientos visibilizados por los periódicos, además lo que se revela es que hay una estrategia diferenciada de los movimientos dependiendo de la pauta de reivindicación. En otras palabras, hay una selección del espacio a partir de la escala de la demanda de los manifestantes (figuras 1 y 2 ).

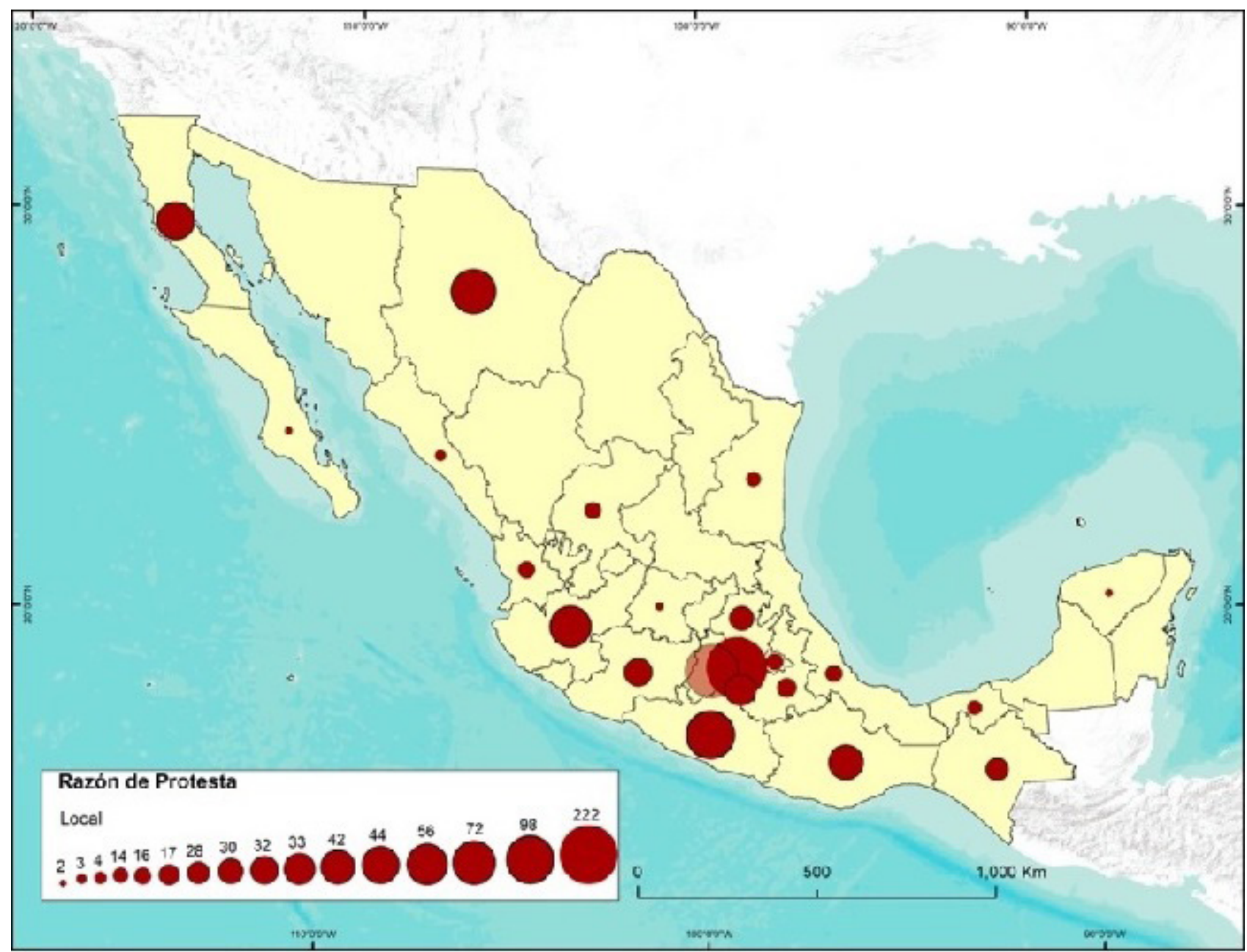

*El objetivo de nuestro trabajo no es demostrar el aumento en numero de las manifestaciones políticas a lo largo del tiempo, por dicha razón, los mapas no se muestran de modo progresivo. Los mapas ilustran la cantidad total en los últimos tres años. 


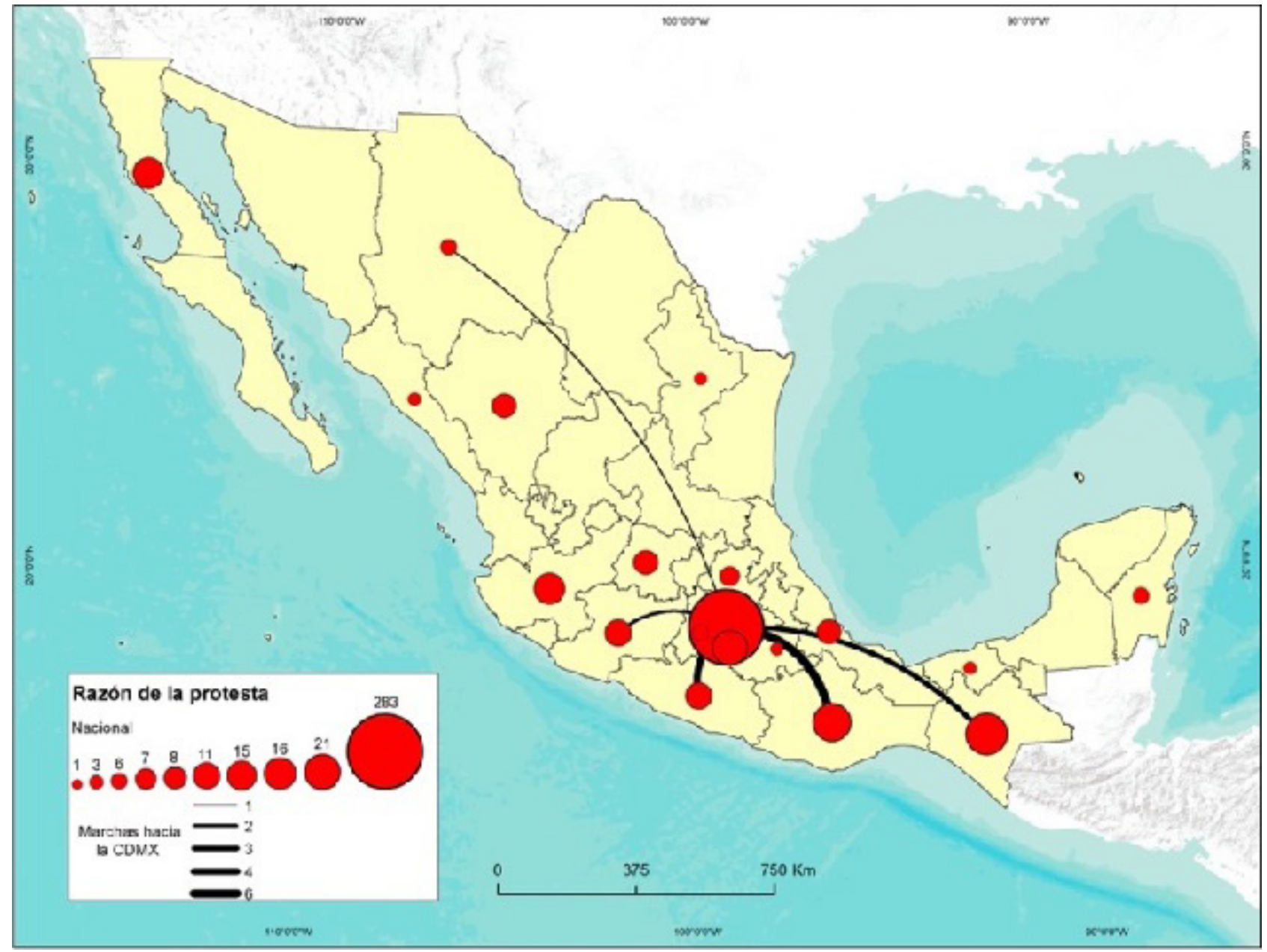

Fuente: Organización própia con datos de El Universal (2015-2018) y La Jornada (2015-2018).

La información obtenida en los periódicos demuestra que hay una gran concentración de protestas de demanda nacional en apenas un lugar: el eje Paseo de la Reformael Zócalo capitalino. De todas las manifestaciones con demanda nacional relatadas por El Universal, el 73\% de todas ellas se encontraban sólo en ese eje, mientras que en La Jornada ese número llega al $67 \%$. Además, hubo varios casos de desplazamientos de personas de diferentes estados hacia ese eje, aun estando a grandes distancias de la capital del país (Figura 2). Además, hubo 81 protestas con demandas internacionales (como crítica al gobierno estadounidense o sobre migración centroamericana y venezolana en el país) y el $95 \%$ de ellos fueron realizados en el eje mencionado. Se destacan como protestas de carácter nacional, manifestaciones contra corrupción y violencia en general, propuestas de leyes que afectan a todo el país (como la reforma educativa y el aumento del precio de la gasolina) y días de protestas en fechas conmemorativas (como el día del trabajo).

En la figura 1 es posible percibir mayor desconcentración de las manifestaciones que poseen demanda local, apareciendo en más estados y en mayores cantidades. Se subraya que las manifestaciones de carácter local ocurridas en la Ciudad de México no fueron en el $95 \%$ de los casos en el eje Paseo de la Reforma - el Zócalo, sino en diferentes calles de las delegaciones y en el campus principal de la Universidad Nacional Autónoma de México, lo cual revela una clara estrategia espacial de las manifestaciones. Se observan como temas recurrentes, las manifestaciones contra asesinatos de personas específicas, reivindicaciones por servicios públicos básicos (asfaltado, luz, agua) y demandas de reconstrucción de casas afectadas por sismos.

Algunos casos llaman la atención sobre las estrategias espaciales de las manifestaciones. El ejemplo de las protestas sobre casos de feminicidios en el campus de la Universidad Nacional Autónoma de México realizados en calles de la propia institución y manifestaciones contra feminicidios en todo el país, ocurridas en el Zócalo capitalino. También los casos de 
las protestas ocurridas en las ciudades de Los Mochis y Culiacán, en el estado de Sinaloa, por el asesinato del periodista Javier Valdez, y dieciséis días después una gran protesta favorable a la libertad de prensa y por el fin de los asesinatos de periodistas en el país llevada a cabo en el Zócalo capitalino ${ }^{7}$.

Existen otras formas de ocupación del espacio que no configura el espacio como político, por ejemplo, el 11 de marzo de 2017 (Lastirini, 2018), a través de un evento denominado "Flamencoton", voluntarios, sacerdotes y personas buscaban recaudar fondos para "Teleton", quienes realizaron un baile con 500 personas para conseguir donativos para la causa. Sin ningún propósito de acción para influir sobre la agenda política, la elección del espacio para el evento fue la Glorieta de la Fuente de Cibeles, en la Colonia Roma Norte de la Ciudad de México. Se subraya que aun cuando está cerca del Ángel de la Independencia en el Paseo de la Reforma, la organización del evento prefirió un lugar reconocido por sus restaurantes y eventos festivos. La materialidad y la fuerza simbólica del Ángel de la Independencia no se conectan con los propósitos de la fiesta, llevándola a otro espacio con diferente significado espacial. La Glorieta de la Fuente seleccionada, por lo tanto, sin el presupuesto de la acción, no se configuró como espacio político, pues, más allá de la característica del espacio público como espacio de la exhibición (Arendt, 2009b), el espacio

7 Pocos son los casos que logran movilizar al país entero para una causa nacional. Los gasolinazos a principios del año 2017 y las protestas organizadas por los sindicatos de los profesores contra la reforma educativa en 2018 son quizás los mayores ejemplos. político posee una intencionalidad específica. Ese ejemplo nos ayudará a comprender adelante el conflicto por el espacio político del Zócalo y las consecuencias del cambio hacia el Estadio Azteca.

La investigación en los dos periódicos reveló que hay una lógica espacial de los movimientos políticos importantes de ser analizada e interpretada, configurándose como un verdadero objeto geográfico (Gomes, 2012). Más que un simple escenario, la selectividad espacial de las manifestaciones demuestra que el espacio es un componente condicionador de ese fenómeno, a partir del momento en que ayuda a visibilizar o invisibilizar las demandas, influenciando más o menos el poder instituyente.

La concentración espacial de las manifestaciones de carácter nacional en el Paseo de la Reforma y en el Zócalo puede ser explicada también por su carga simbólica, construida históricamente a lo largo de todo el trayecto que une esos dos espacios. Los monumentos (como estatuas, obeliscos, palacios) son representaciones materiales de valores políticos transmitidos en un tiempo pretérito, participando del paisaje de determinados espacios específicos de la ciudad (Corrêa, 2012). Los actos políticos se eternizan en el espacio a través, por ejemplo, de monumentos y toponimias de calles y plazas, y pasan a funcionar también como impulsores de nuevos actos políticos ocupados y legitimados por los ciudadanos.

La figura 3 revela el trayecto recorrido por las manifestaciones apuntadas en los mapas anteriores. Hay

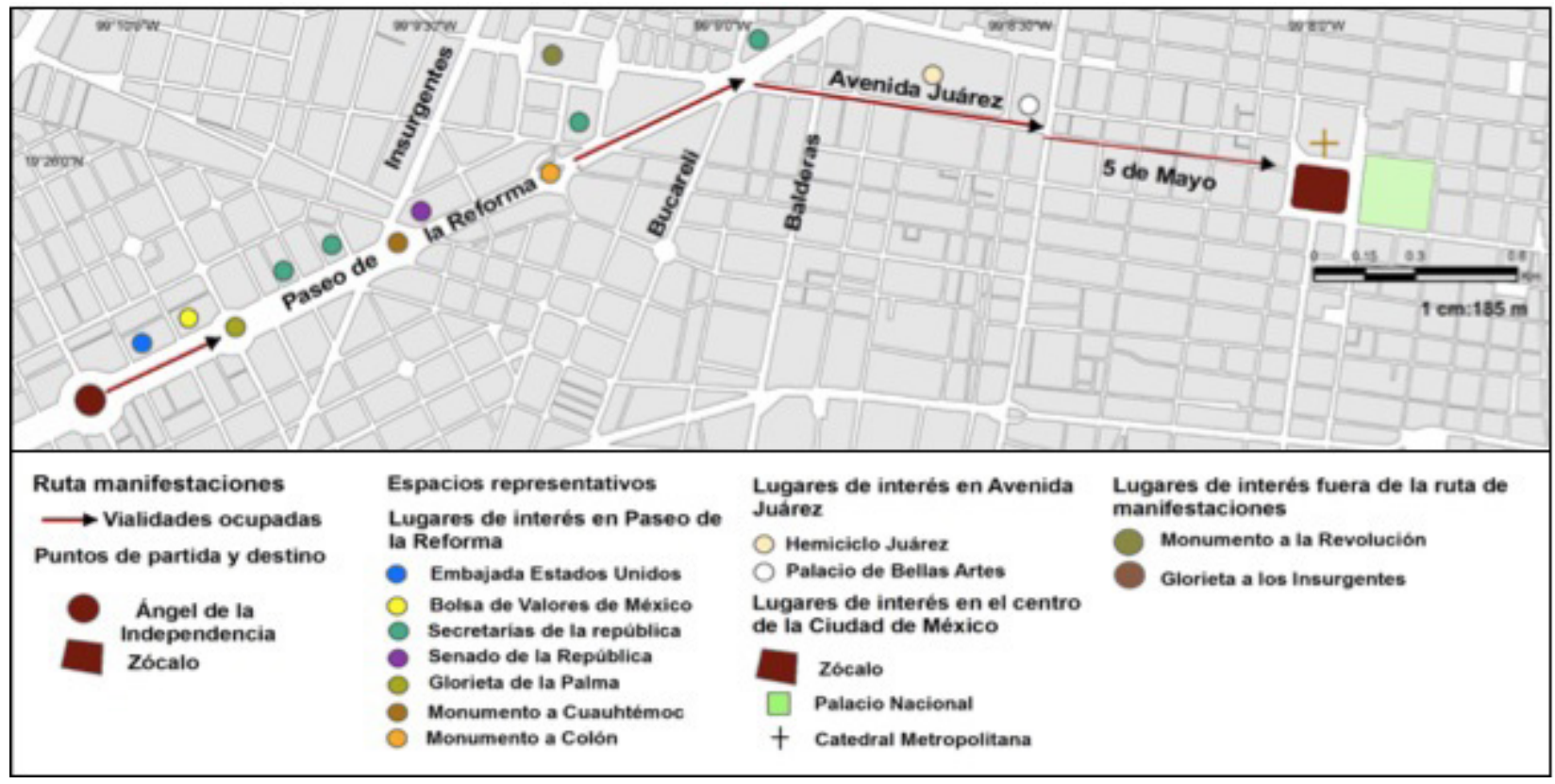


una intensa concentración material simbólica en ese eje, desde la Embajada de EEUU, como diferentes secretarías de gobierno, culminando en el Palacio de Gobierno en el Zócalo. Más aún, hay monumentos construidos por todo el eje, como el Ángel de la Independencia, los monumentos a Cuauhtémoc y a Colón, además de que en todo el trayecto de Paseo de la Reforma se encuentran artefactos y mobiliario urbano que refleja su potencialidad política. Una manifestación con ese escenario posee otra fuerza, transformando el espacio, simultáneamente, en escenario y platea. El Zócalo capitalino es considerado la plaza pública más importante del país, localizado en uno de los centros históricos más estudiados de la República mexicana. Desde la época prehispánica, la independencia mexicana, hasta la actualidad ha sido un espacio público que ha cobrado importancia política en Mexico. En su centro hay una bandera inmensa del país, con edificios políticos importantes para la historia $\mathrm{y} / \mathrm{o}$ para la actualidad (como el palacio de gobierno).

El 23 de junio de 2018, la marcha del orgullo LGBTTTI (Lésbica, Gay, Bisexual, Transexual, Transgénero, Travesti e Intersexual) reunió a 250 mil personas bajo el lema "40 años viviendo en libertad, ¡No renunciaremos!", cuyo camino comenzó en el Ángel de la Independencia y terminó en el Zócalo capitalino. Aunque ese evento es reconocido por sus carros alegóricos y ambiente de fiesta, la selección del trayecto demuestra que es una gran manifestación política. Al acompañar todo el camino recorrido, es interesante percibir la interacción existente entre el público y el espacio resignificando la propia marcha a través de rituales específicos, por medio de los elementos simbólicos existentes y la disposición espacial de los objetos. La velocidad de la manifestación cambia a partir de su paso por símbolos espaciales, como el Ángel de la Independencia y el monumento a Cuauhtémoc.

Esto ocurre por dos características espaciales: primero, el formato de rotonda, que acaba por dividir la manifestación en dos partes, perdiendo velocidad al encontrar un obstáculo en su camino. Segundo, esos formatos en grandes cruces a lo largo de la avenida tienen como funcción destacar el elemento simbólico que se encuentra en el centro, forzando a todos los transeúntes y vehículos a cambiar de trayectoria y rodear el monumento. Sin duda, esto agrega más valor simbólico, además del significado existente en la propia construcción. El Ángel de la Independencia es quizás una de las mayores marcas espaciales simbólico-políticas del país y por esa razón la marcha LGBTTTI lo rodeó con sus banderas, canciones y gritos. Hacer esto es un acto de intensa carga simbólica. El mapa anterior (Figura 3) revela objetos y marcas espaciales relevantes en la construcción del imaginario social, cuya presencia se relaciona directamente con las manifestaciones que allí ocurren.

La conexión cada vez más fuerte entre el mundo virtual y el material, a partir de usos generalizados de smartphones con cámaras de buenas resoluciones conectadas automáticamente a Internet y a redes sociales con fuerzas de propagación hace la teatralidad aún más importante que antes, pues es un modo de atraer la atención de las cámaras y alcanzar a un mayor número de personas de la sociedad. La importancia de la opinión pública sobre el uso del espacio político abierto es un factor fundamental para comprender las actuaciones de los manifestantes. Según Parkinson (2012, p.69), "Ios activistas políticos entendieran hace años, que no es el problema en sí que recibe cobertura, es la dramatización del problema, y que muchas veces requiere acción física, creando imágenes y una historia, en el espacio público [político] físico".

La estrategia de elección del espacio también se asocia a su tamaño. Se destaca que el Zócalo capitalino tiene capacidad de recibir hasta 60 mil personas, caso diferente entre los espacios públicos del país. Siendo una plaza su formato espacial no lleva al movimiento de los manifestantes, sino a su concentración. El contraste entre el tamaño del espacio político y la cantidad de participantes puede tener efectos positivos o negativos para la intencionalidad de la protesta, es decir, las demandas serán ampliamente divulgadas y tendrán más posibilidades de afectar la agenda política si el efecto manifestación/espacio político es mayor. Así, una manifestación que consiga ocupar todo el espacio del Zócalo tendría un gran impacto político.

Las calles y las plazas poseen potencialidades de visibilidades diferentes. Como Gomes (2012) apunta, la calle es una invitación al movimiento, que nos induce al avance; ya las plazas son intervalos en la continuidad de las calles, abriendo actividades que nos hacen permanecer, o al menos cumplir un circuito. Sin embargo, las marchas y las ocupaciones no están atrapadas a estas formas, pero pueden transponerlas a través de circuitos que se conecten unas con otras, siendo posible que una marcha termine en una ocupación o una ocupación esté asociada a la marcha (Machado Filho, 2018). Las características materiales ayudan a entender por qué los movimientos comienzan en el Paseo de la Reforma y terminan en el Zócalo, y no al revés.

Adiferenciadeautoresqueconsideranlosmovimientos políticos como un bloque homogéneo (Gomes \& Ribeiro, 2018), se percibe la inmensa heterogeneidad entre los participantes de un evento, donde, en el espacio político, es posible la convivencia entre los integrantes 
de la marcha y de los externos. A pesar de estar unidos bajo el mismo objetivo general, los grupos que forman parte de la gran diversidad de la Comunidad LGBTTTI, muchas veces no conviven cotidianamente, pero en el día de la marcha compartieran y vivieran el espacio político abierto para actuar en la agenda política. Se suma a esto el hecho de que en el evento de 2018, la convergencia entre participantes de la gran marcha y aficionados conmemorando la victoria mexicana en el partido por la Copa del Mundo de fútbol en el Ángel de la Independencia, generó una mezcla plural entre banderas del arcoíris y la bandera mexicana, coexistiendo en el mismo espacio bajo el signo de la civilidad, pero también por la existencia de aparatos policiales que garantizaron la convivencia de los diferentes participantes.

Además, como hay una lucha por visibilidad, el uso del espacio político también está sujeto a las disputas entre diferentes grupos. Es el caso también de las elecciones presidenciales mexicanas en 2018.

La disputa por el espacio político del Zócalo en las elecciones presidenciales mexicanas de $\mathbf{2 0 1 8}$

La decisión de realizar el cierre de campaña de Andrés Manuel López Obrador (AMLO) del partido Morena (partido político de izquierda que tiene como lucha principal la idea de cambio en relación a los dos partidos principales de México, PRI y PAN) en 2018 en el estadio Azteca no fue sencillo o sin conflictos. Todas las encuestas de opinión apuntaban que el candidato ganaría con gran margen de diferencia y, por esa razón, AMLO deseó terminar sus meses de campaña en el Zócalo capitalino. Sin embargo, el gobierno de la Ciudad de México, en aquel momento liderado por un partido diferente, negó la solicitud del candidato y su partido para realizar el cierre de campaña en el Zocalo capitalino. La noticia de la negación del uso de Zócalo por AMLO repercutió en todos los grandes periódicos del país, como Excelsior, El Universal, El Financiero, Milenio, La Jornada y Reforma, entre otros.

Andrés Manuel López Obrador afirmó que negar el Zócalo para su cierre era "arbitrario", "inexplicable" y "autoritario" (Gonzalez, 2018; Parente, 2018; Monroy, 2018). Según él, su probable victoria estaba irritando a sus adversarios, como el entonces gobernador del Distrito Federal. Para García de la revista Proceso (García, 2018), no permitir el cierre en el Zócalo fue el epilogo de las limitaciones creadas por opositores a lo largo de la campaña, pues, según la página virtual, políticos adversarios habían creado obstáculos a diecisiete actos masivos y, al menos en dos, había claras señales de sabotaje.
En respuesta, se creó una petición en la internet para presionar al gobierno capitalino a ceder. A través de change.org, los organizadores pedían que el gobernante "se comporte de manera democrática", pues, según ellos, la negativa obedecía a motivos políticos y no logísticos. La petición afirmaba que "el espacio público es de todas y todos, y el Zócalo de nuestra capital ha sido el lugar en el que convergen distintas luchas y movimientos sociales por la democratización de nuestro país. ¡Defendámoslo" (Change, 2018).

El gobierno capitalino alegó dificultad logística, pues todo el espacio ya estaba montado para el evento deportivo Zocafut, con grandes pantallas para que los ciudadanos pudieran acompañar los partidos de la Copa del Mundo de fútbol de Rusia. Afirmó que la desestimación no tenía nada que ver con las motivaciones políticas (Figura 4).

Figura 4- El Zócalo capitalino cerrado

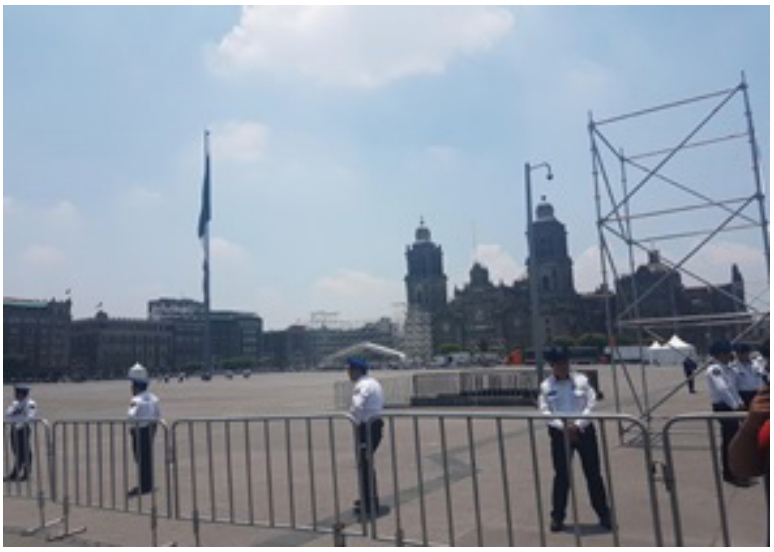

Fuente: Próprio autor, día 20 de junio de 2018

En la figura 4, una semana antes del cierre de la campaña de AMLO, se observó que toda la plancha del Zócalo capitalino estaba cerrada y con policías para controlar el acceso. Sin embargo, la imposibilidad de un evento de gran tamaño en el Zócalo debido a la infraestructura montada no fue motivo para negar su uso a la Marcha LGBTTTI, que ocurrió cuatro días antes de la fecha del cierre de campaña, cuando fue posible el uso del espacio por miles de personas, incluso con pantallas y otros equipos en la plaza. Defendemos que el cambio de cierre de campaña hacia el estádio Azteca (Figura 5) es el resultado de un conflicto por el espacio político abierto.

Debido al debate teórico sobre la relación entre espacio político y democracia y el mapeo previo de la concentración de los movimientos políticos en el país, la alteración de la localización del cierre de campaña no nos pareció algo trivial. Al contrario, como geógrafos, la consideración del espacio geográfico como actor y no como un simple escenario es algo inherente a 
Figura 4- El Zócalo capitalino cerrado

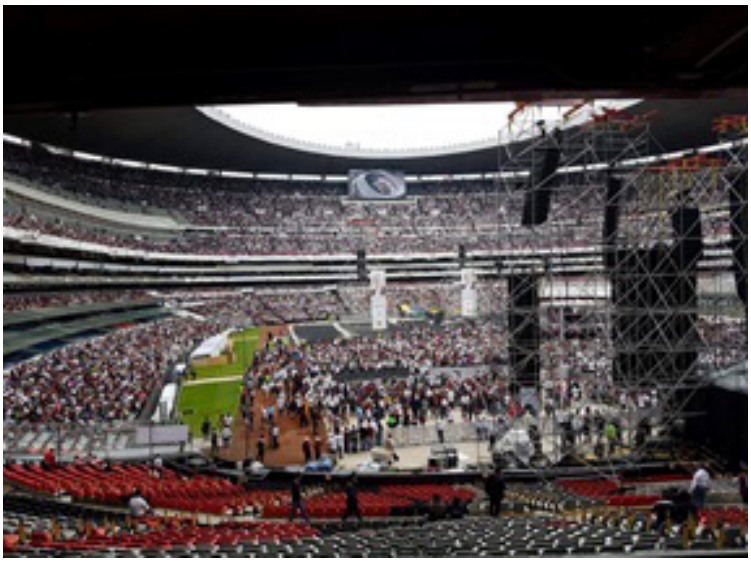

Fuente: Próprio autor, día 27 de junio de 2018.

nuestra mirada. Por esa razón, dos preguntas surgieron: ¿hay diferencia en realizar el cierre de campaña en el Zócalo o en el estadio Azteca? ¿De qué modo la clave interpretativa del espacio político podría ayudarnos a entender los diferentes significados posibles al uso de los dos lugares?

Las respuestas recibidas por los ciudadanos participantes del cierre la campaña en el día 27 de junio de 2018 convergieron con las presentadas por miembros de la campaña. En cuanto a los surveys realizados, el $72 \%$ de las personas afirmaron que el Zócalo sería un mejor lugar para el evento que el estadio Azteca; ya que en las entrevistas con participantes del partido Morena, ese número llegó al 92\%, demostrando una diferencia notable entre los dos grupos informantes, en cuanto a los dos lugares, el Zócalo y el estadio Azteca.

Importante señalar que el estadio Azteca es considerado dentro del fútbol mexicano el más importantes, es el más grande del país. Se encuentra en la alcaldía Coyoacán al sur poniente de la Ciudad de Mexico. Es la casa del equipo America de los más famosos, gracias a la cantidad de seguidores con los que cuenta, además de ser sede de la final del Mundial de 1970, don la selección Brasileña ganó la Copa ante Italia.

Las respuestas recibidas en la encuesta que justificaban la preferencia por el estadio Azteca fueron casi todas relacionadas a un aspecto espacial material: la mayor capacidad de confort proporcionado por el espacio. El $19 \%$ de las personas dijeron preferir ese lugar debido a la existencia de sillas, vendedores de comidas y bebidas que venían a su encuentro y cobertura contra posible lluvia (en gran parte del estadio). El 7\% de los encuestados apuntaron un valor simbólico que se refleja en la intencionalidad existente en la celebración: el cierre en el estadio daría un carácter más informal, relajado y festivo, en contraposición a Zócalo que, según dos entrevistados, "haría más serio el evento".
Por último, el $2 \%$ afirmó que preferían el estadio por cuestiones personales, como proximidad a sus residencias. La única persona de la campaña del candidato que afirmó que el cierre sería mejor en el estadio Azteca resaltó un elemento material del espacio: allí sería posible crear espacios más distintos de ocupación de los participantes. Como se observó el día del evento, había diferencias espaciales de uso del espacio distinguiendo integrantes del partido y simples ciudadanos (ver Figura 5). Las personas con contactos accedían al césped con sillas en fila; quienes tenían conocidos más influyentes conseguían en el césped pasar una barrera colocada y llegar cerca del escenario, donde estarían los artistas y el candidato. Como se observó en la fecha (Figura 5), los ciudadanos comunes se encontraban en las gradas, más lejos del corazón de la ceremonia.

En contraposición a las justificaciones dadas para la preferencia por el estadio Azteca, los defensores del Zócalo, tanto los participantes como los miembros del partido, destacaron más características inmateriales e intencionales que materiales. Los primeros (89\%) respondieron que el Zócalo es "emblemático" y "la fuerza del Zócalo" "dificultaría un posible fraude electoral". Muchos también recordaron el historial del candidato, al afirmar que "pensaron que en el Zócalo sería el gran desenlace de las elecciones de 2006 y de 2012, durante las cuales AMLO intentó alcanzar la presidencia y no lo logró". Sin embargo, se observa que el "simple" cambio de localización del evento sería, para muchos entrevistados, capaz de ejercer mayor fuerza contra una supuesta adulteración de los votos el 1 de julio. Otra vez es importante señalar la fuerza inmaterial y intencional de los espacios políticos.

Además, dos encuestados afirmaron que en el Zócalo habría una mayor preocupación de cobertura de los medios para el evento, pues el impacto de una foto con la plaza completamente ocupada sería más fuerte que la de un estadio de fútbol, generando mayor visibilidad, elemento fundamental para un espacio político. Por último, el $11 \%$ de los informantes afirmaron que el Zócalo sería mejor debido a la facilidad de medio de transporte. En el día del evento fue visible la gran dificultad para llegar y salir del estadio Azteca: largos atascos se formaban y la salida de las 90 mil personas fue caótica.

Miembros del partido afirmaron que realizar en el Zócalo "daría otro sentido para el cierre, pues es un hito del país". La comparación entre los dos espacios hizo evidente sus diferencias simbólicas y políticas: según tres integrantes, "el significado del estadio Azteca es contra todo lo que defendemos", pues "el estadio forma parte del grupo Televisa, la 'mafia del poder' que estamos denunciando desde hace muchos años y sería la casa de 
un equipo de fútbol que hace muchas trampas". Además, para otro partidario, el "estadio Azteca representa el status quo en contraste con el Zócalo que es más del pueblo", pues el primero, además de todo, "es privado, mientras que el segundo es público".

Por último, los integrantes del partido aún destacaron dos elementos materiales que justifican el uso del Zócalo: "en el estadio Azteca será necesario control de entrada con boletos, pues sería peligroso dejar entrar sin límite", en cambio en el Zócalo la ocupación es infinita. A pesar de que la plaza soporta alrededor de $60 \mathrm{mil}$ personas, las calles a su alrededor funcionan como una gran red de drenaje que confluye aguas de todas partes y desembocan en su corazón principal, además de su red de transporte público que permitiría asistir a más personas al evento.

Para todos los integrantes entrevistados del partido Morena, la negación del Zócalo tuvo como único objetivo disminuir la fuerza del candidato en las vísperas de la elección. El potencial de visibilidad de ese espacio hace que el Zócalo sea objecto de conflictos de uso. En otras palabras, al cambiar del Zócalo al estadio Azteca, AMLO modificó completamente el sentido del cierre de campaña: de un movimiento político contestatario, se transformó en un evento festivo. Presentar su plan de gobierno en el Zócalo, espacio político abierto con mayor simbolismo político del país y con condiciones materiales mejores que el estadio Azteca (como tamaño e infraestructura de transporte), dirigiría su texto directamente al poder político representado por el Palacio de Gobierno que allí se encuentra.

Desde 1994 en el "Éxodo por la democracia", Andrés Manuel López Obrador se configuró como un actor político importante en el uso del espacio del Zócalo. Su nombre fue siempre contra la política tradicional y él es conocido por sus ataques a los partidos políticos dominantes en el escenario mexicano (PRI y PAN). La "marca" AMLO se construyó también con el uso de tal espacio político abierto, como narrado en Amanecer en el Zócalo - Los 50 días que confrontaron a México (Poniatowska, 2007) sobre los marcados momentos relacionados con la derrota de AMLO en las elecciones de 2006 y su indignación registrada en la plaza principal del país. El Zócalo se convertía entonces en el mayor tesoro del candidato contestatario, espacio y sujeto se convertirían en un solo que se retroalimentaría simbólica y políticamente.

La concentración de movimientos políticos en el eje Paseo de la Reforma-el Zócalo, como se reveló en la espacialización realizada, es producto y condicionante de su centralidad/polaridad política en el país. Ser la capital del país no justifica el tamaño de la polarización de las manifestaciones políticas, principalmente en un Estado Federativo de grandes proporciones territoriales, como es México, y con amplia difusión de medios de comunicación. La interpretación de ese fenómeno presupone comprender las particularidades del escenario político mexicano.

De manera que si esos espacios políticos abiertos funcionan como verdaderas armas de potencialización de los movimientos políticos, la polaridad acentúa los conflictos, hace la manifestación más propicia a la intervención y la invisibilización de su movimiento. Por eso, diferentes grupos - medios, candidatos políticos y empresarios locales - empiezan a construir un discurso que condena el uso del espacio político abierto Paseo de la Reforma-Zócalo. En suma, la polaridad de ese continuo espacio político abierto al mismo tiempo que colabora con la mayor visibilidad del fenómeno, también acaba por concentrar el poder de acción en una localidad, dificultando la participación y la capacidad del ciudadano mexicano en influir y presionar el poder público.

En regímenes democráticos maduros el poder está más ampliamente distribuido que en los regímenes autocráticos (Bobbio, 2017). En ellos se encuentra el fenómeno que hoy se denomina poder "difuso", es decir, una de las características de la sociedad democrática es la de tener varios centros de poder, de ahí el término "poliarquía" de Robert Dahl (2009). El poder es más difuso cuando el gobierno de la sociedad es más regulado por procedimientos que "admite la participación, el disenso y, por lo tanto, la proliferación de los lugares que se toman decisiones colectivas" (Bobbio, 2017, p.105). Como afirman Levi \& Garmendia (2008), a pesar de que en la Constituición mexicana el país se concibe como una federación, "es indudable que el Estado mexicano ha sido eminentemente centralizado" (p.126). La ya conocida polarización de la Ciudad de México como espacio de mando para todo el territorio nacional (Carmagnani, 2016), políticamente y económicamente, se refleja también en el uso de los espacios políticos abiertos. Descentralizar de verdad la federación mexicana a partir de la escala local favorece un proyecto de nación que "busca transitar hacia un federalismo mejor construido" (Levi \& Garmendia, 2008, p.127), con fuerte impacto también en la espacialización de las protestas.

La pedagogía de la democracia gana fuerza con la descentralización, especialmente en un país con dimensiones territoriales como México, por mejorar el contacto de la población con la política. El individuo hacia y de la democracia, no es algo natural, sino una construcción social realizada también en los espacios políticos, pues es por medio de ellos que se dan la administración de la multiplicidad y la construcción de 
sujetos democráticos. Las manifestaciones no son divergentes al sistema democrático; por el contrario, espacios políticos abiertos forman parte de la esencia misma de ese sistema político. La percepción política de la multiplicidad y multilateralidad se construye en la coexistencia de los diferentes actores que, juntos, actúan en torno a una agenda política. La geografía puede, a partir incluso de sus clásicos traer el debate sobre cómo concentración/desconcentración afectan las relaciones socio-espaciales y en ese caso explícitamente políticoinstitucional.

Como la democracia liberal se propone, la concentración de poder es perjudicial para la sociedad, pues permite abusos, como el intento de prohibición e invisibilización de ciertas posiciones e ideologías político-partidarias. La negación para el uso del Zócalo por un candidato opositor al gobierno capitalino reveló que la selección espacial del fenómeno condiciona su significado a partir del momento en que el estadio Azteca no seconfigura como un espacio político. La configuración del estadio Azteca como espacio no político se debe a la información observada en las encuestas y en el trabajo de campo. Como fue presentado en el marco teórico, la materialidad, inmaterialidad y la intencionalidad de los espacios políticos caminan juntas, es decir, hay características fundamentales para la democracia, como el modo que la población identifica el espacio. Fue señalada la idea de espacio público como característica inmaterial y la acción como elemento intencional que desaparecen en el uso del estadio Azteca - de un evento de protesta se cambió a una festividad. Es posible hacer una comparación con los ejemplos mencionados en el marco teórico: la Marcha del Orgullo LGBTIII en el eje Paseo de la Reforma-el Zócalo y el Flamencoton en la Glorieta de la Fuente de Cibeles. La selección del espacio es un reflejo y condiciona el carácter político de los usos espaciales.

La desconcentración favorece la democracia, ataca intentos despóticos y favorece la libertad del individuo. Es posible transponer esto también para reflexionar sobre el espacio político abierto: la pedagogía de la democracia y la actuación sistemática de los movimientos políticos necesitan una desconcentración de uso, en busca de alcanzar más grupos en diferentes partes del país, disminuir la fuerza de grupos oligárquicos que, poseyendo recursos para la locomoción en largas distancias para llegar al Paseo de la Reforma y el Zócalo, monopolizan el uso del espacio, visibilizando sus movimientos y oscureciendo otros. Cómo cambiar ese escenario es el gran desafío de los grupos que buscan en el uso del espacio político abierto su influencia y presión sobre el Estado. La desconcentración fortalece la acción.

\section{Consideraciones finales}

La idea general de este artículo fue presentar una mirada geográfica a la democracia. A partir de la presentación de valores de la democracia, se definió el concepto de espacio político y su tipología (exclusivo, limitado y abierto) y se buscó traerlo como escenario y platea, es decir, escenario para la realización de grandes acciones, discursos y palabras y platea capaz de dar testimonios de los mismos y condicionar nuevos eventos. Se defendió que donde ocurre la manifestación es un importante elemento de visibilidad, incluso a través de los medios.

Como se percibió en la tabulación de los datos obtenidos en la investigación, hay una intensa concentración de las protestas de demanda nacional en el eje Paseo de la Reforma-Zócalo capitalino, mientra que las manifestaciones de demanda local son menos concentradas. Además de la ya conocida concentración económica y demográfica del país alrededor de su capital, se reveló también la polarización de este eje como espacio político abierto. Sin duda, la geografía de las protestas nos permite entender otras geografías, como la discusión acerca de la concentración políticoeconómica de todo un país alrededor de una sola zona metropolitana. Se demostró que además de diversas cuestiones de orden económico ya conocidas (desde la fuerte disparidad regional que refleja en condiciones desiguales en el territorio mexicano), la concentración político-económica y político-simbólica de la Ciudad de México afecta directamente la democracia cotidiana en el país. Además, la espacialidad de las protestas es un reflejo de un federalismo que aún sigue muy concentrado en la región metropolitana de la Ciudad de México.

Por eso, hay intentos insistentes de criminalizar esas manifestaciones, ya sea en los medios o incluso por los candidatos políticos, como se presentó en el apartado introductorio. La dependencia de un espacio político para la vocalización de sus intereses expone la fragilidad de esos grupos. La geografía de la democracia es otra interpretación que nos ayuda a comprender el sistema político que, al mismo tiempo que se expande por el mundo, tiene su legitimidad cada vez más en riesgo. 


\section{Referencias}

ARENDT, H. (2009a) O que é Política? Rio de Janeiro: Bertrand Brasil. (2009b) Condição Humana. Rio de Janeiro: Bertrand Brasil. (2009c) A promessa da política. Rio de Janeiro: Bertrand Brasil.

ARREDONDO, I. (2018). Padece CDMX 10 mil marcha en trés años. El Universal. Disponible en: https://www.eluniversal. com.mx/periodismo-de-investigacion/cdmx-9-marchasal-dia-por-3-anos. Acesado 10 de marzo 2018.

AZEVEDO, D. A. (2018a) Modelos de democracia e espaços políticos: o caso da democracia participativa. Revista Geografares, n.26, v.1, p.126-146.

. (2018b) Os limites da democracia participativa: uma análise a partir dos Conselhos Municipais no Rio de Janeiro. GEOgraphia, vol.20, n.43, p. 54-70.

(2019) Evaluation of the democratic system from the qualification of political spaces: the case of Cuauhtémoc (México). L'Espace Politique, n.39, v.3, p.1-25.

AZEVEDO, D.A.; SOTELO, L. S. P. (2018) La ingeniería político-geográfica de la democracia participativa en la Ciudad de México: los Comités Ciudadanos. Revista Espaço Aberto, v.8, n.1, p.7-24.

BOBBIO, N. (2000) O futuro da democracia. São Paulo: Paz e Terra.

(2007) Do fascismo à democracia. Rio de Janeiro: Elsevier.

(2017) Liberalismo e democracia. São Paulo: Edipro.

CARMAGNANI, M. (2016) (coord.). Federalismos latinoamericanos: México, Brasil y Argentina. Fondo de Cultura Economica.

CASTRO, I. E. (2012) O espaço politico: limites e possibilidades do conceito. En I. E. Castro; P. C. Gomes; R. L. Corrêa (Coords). Olhares Geográficos modos de ver e viver o espaço (pp.43-73). Rio de Janeiro: Bertrand Brasil.

(2018) Espaço Político. GEOgraphia, v.20, n.42, p.120-126.

CASTELLS, M. (2015) The egyptian revolution. En J. Goodwin; J. M. Jaspers (Coords.). The social movements reader. Cases and concepts, 3ed, Oxford: Wiley Blackwel, p. 45-52.

CHANGE. (2018) Exigimos al GBCDMX nos preste al pueblo NUESTRO Zócalo para el cierre de campaña de AMLO. Disponible en: https://www.change.org/p/exigimos-al-gobcdmx-nos-preste-al-pueblo-nuestro-zócalo-para-cierre-decampaña-de-amlo. Acesado dia 10 de julio de 2018.

CISTERNAS, P. T. F.; CONTRERAS, R. A. S.(2018) Resiliencia comunitaria frente a los desastres naturales: caleta Tumbes, región del Biobío, Chile. Cuadernos de Geografía: Revista Colombiana de Geografía, vol. 27, n.1, pp.131-145.

CODATO, A. (2011) O espaço politico segundo Marx. Crítica Marxista, v.32, pp.33-56.

CORRÊA, R. L. (2012) Espaço e simbolismo. En I. E. Castro; P. C. Gomes; R. L. Corrêa (Coords). Olhares geográficos: modos de ver e viver o espaço Rio de Janeiro: Bertrand Brasil, p.70-86.

COX, K.; D. R. REYNOLDS; S. ROKKAN (Edts) (1974) Locational approaches to power and conflict. New York: Sage Publications.

DAHL, R. (2009) Sobre a democracia. Brasília: Universidade da UnB.

FLORES-MARQUEZ, D. (13 diciembre 2016). Movimientos sociales e internet en Mexico. Democracia Abierta. Disponible en: https://www.opendemocracy.net/democraciaabierta/dorismilda-flores-m-rquez/movimientos-sociales-e-interneten-m-xico. Acesado día 10 de diciembre de 2018.

GARCIA, A. R. (3 junio 2018). Gobierno de la CDMX niega el Zócalo a López Obrador para su cierre de campaña. Proceso. Disponible en: https://www.proceso.com.mx/537011/gobierno-de-la-cdmx-niega-el-zocalo-a-lopez-obrador-para-sucierre-de-campana. Acesado dia 04 de junio de 2018.

GOMES, P. C.C. (2012) Espaços públicos: um modo de ser do espaço, um modo de ser no espaço En I. E. Castro; P. C. Gomes; R. L. Corrêa (Coords). Olhares geográficos: modos de ver e viver o espaço, Rio de Janeiro: Bertrand Brasil, pp.1942.

GOMES, P.C.C.; RIBEIRO, L. P. (2018) Espaços públicos como lugares da política. Revista Geografares, n.26, pp.5-11. GONZALÉZ, Isabel. (06 junio 2018). AMLO cerrará su campaña en el Estádio Azteca. Excelsior. Disponible en: https:// www.excelsior.com.mx/nacional/amlo-cerrara-su-campana-en-el-estadio-azteca/1243542. Acesado en 7 de junio de 2018.

GUAZO, D. (02 marzo 2017). CDMX, ciudad de marchas y pérdidas milionárias. El Universal. Disponible en: http:// www.eluniversal.com.mx/articulo/periodismo-de-datos/2017/03/2/cdmx-ciudad-de-marchas-y-perdidas-millonarias. Acesado día 21 de junio de 2018a. 
GILTIN, T. (1980) The world is watching: mass media in the making and unmaking of the New Left. Berkeley: University of California Press.

HALL, J. (1992) (org.) Os Estados na história. Rio de Janeiro: Imago.

HELD, D. (2012) Modelos de Democracia. Madrid: Alianza Editorial.

HERNANDEZ, E. (22 noviembre 2017). Sufre la capital del país por marchas y violencia. El Universal. Disponible en: https://www.eluniversal.com.mx/metropoli/cdmx/sufre-la-capital-del-pais-por-marchas-y-violencia. Acesado dia 10 de marzo de 2018.

KELSEN, H. (2000) A Democracia. São Paulo: Martins Fontes.

JUWER, V. V. S. (2012) A Geografia eleitoral dos grupos criminosos territorializados na cidade do Rio de Janeiro. Dissertação de Mestrado, PPGG, UFRJ.

LASTIRINI, D. (11 marzo 2018). Realizan baile flamenco en la Fuente de las Cibeles para apoyar al Teleton. El Universal. Disponible en: http://www.eluniversal.com.mx/nacion/sociedad/realizan-baile-flamenco-en-la-fuente-de-las-cibelespara-apoyar-al-teleton. Acesado dia 14 de marzo de 2018.

LEE, N. K. (2009) How is political public space made? - the birth of Tiananmen Square and the May Fourth Movement. Political Geography, n. 28, pp. 32-43.

LEVI, L. L; GARMENDIA, E. S. R. (2008) Federalismo y redistritación electoral en México, Política y Cultura, núm. 29, p. 125-147.

LEVY, J. (1999) Le tournant géographique, Paris: Belin.

MANN, M. (1992) O poder autônomo do Estado: suas origens, mecanismos e resultados. En J. Hall (ed.). Os Estados na história. Rio de Janeiro: Imago, p.10-42.

MACHADO FILHO, G. F. (2018) Dos espaços da sociabilidade aos espaços da ação política: transfiguração de ruas e praças em espaços políticos. Revista Geografares, n.26, p.214-234.

MAGDALENO, F. S. (2010) A territorialidade da representação política: vínculos territoriais de compromisso dos deputados fluminenses. São Paulo: Annablume.

MERCA 2.0. Los periodicos mas leídos en Mexico - 2017. Disponible en: https://www.merca20.com/-leido-los-mexicanos/. Acesado en 15 de febrero de 2018.

MITCHELL, D. (2003) The right to the city. Minneapolis: Minnesota University Press.

MONROY, J. (06 junio 2018). Andrés Manuel López Obrador cerrará campaña en el Estádio Azteca. El Economista. Disponible en: https://www.eleconomista.com.mx/politica/Andres-Manuel-Lopez-Obrador-cerrara-campana-conevento-artistico--20180606-0074.html. Acesado dia 07 de junio de 2018.

NUNES, J.; Sanfelici, D. (2018) Ambiente institucional e diversidade territorial: considerações para uma agenda de pesquisa. Geographia, v.20, n.44, p.18-35.

PAINTER, J.; JEFFREY, A. (2009) Political Geography. Washington D.C.: SAGE.

PARENTE, L. (04 junio 2018). "Arbitraria” la negativa para usar el Zocalo de CDMX: AMLO. La Jornada Disponible em: http://lajornadasanluis.com.mx/nacional/acto-arbitrario-negarme-el-zocalo-en-cierre-de-campana-amlo/. Acesado dia 05 de junio de 2018.

PARKINSON, J. R. (2012) Democracy and Public Space. Oxford University Press.

PASTRANA, D. (2011) El delito de protestar en Mexico. En P. Rincon, N. Magrini y R. Rabinovich (Coords). Vamos a portarnos mal Documento núm.12, Bogotá, p.23-49.

PONIATOWSKA, E. (2007) Amanecer en el Zocalo: los 50 días que confrontaron a Mexico. Ciudad de Mexico: Editorial Planeta Mexicana.

RESNICK, D. (2017) Democracy, decentralization, and district proliferation: the case of Ghana. Political Geography, vol.57, July, pp.47-60.

ROVIRA-SANCHO, G. (2013) Activismo mediático y criminalización de la protesta: médios y movimentos sociales en México. Revista Convergencia, num.61, enero-abril, pp.35-60.

SECOR, A. J. (2010) Social surveys, interviews, and focus group. En B. Gomez; J. P. Jomes III (Coords). Research Methods in Geography: a critical introduction Oxford: Wiley-Blackwell Editor, p.194-206.

SEPULVEDA, U. M. S. (1992) Recuperando la espacialidad de los sujetos: metodologías cualitativas para el análisis espacial, un modelo de topos, paisajes y tecnologías. Investigaciones Geográficas, n. 96, Agosto, pp.1-22, 2018. SMITH, A. D. Criação do Estado e a construção da nação. En J. Hall (ed.). Os Estados na história. Rio de Janeiro: Imago, p.334-385.

TILLY, C. (2007) Democracy. Cambridge: Cambridge University Press. 